\section{CELEBRATING 40 YEARS OF CLINICAL EVIDENCE}

GSK, manufacturer of Corsodyl mouthwash, is celebrating the anniversary of the first clinical evidence for dental application of the chlorhexidine digluconate formulation. Corsodyl can be recommended for a range of dental treatment needs including:

- Treating gingivitis ${ }^{1-3}$

- Supporting oral health in compromised patients where toothbrushing cannot be adequately employed

- Supporting effective gum healing after surgery

- Helping to resolve denture stomatitis ${ }^{4}$

- Helping to aid to healing in acute candidiasis.

This is why Corsodyl remains the most recommended medicated mouthwash by dental experts in the UK. ${ }^{5}$ Corsodyl mouthwash has a proven heritage in treating gum problems. Chlorhexidine digluconate is a double positive charged molecule enabling it to bind to negatively charged surfaces including teeth, mucous membranes and bacteria. Once on the surface, chlorhexidine repels bacteria by creating a protective shield over the teeth and gums. This substantivity means chlorhexidine is available for up to 12 hours post-rinsing for around the clock protection against bacteria. ${ }^{6}$

For further information visit www.gsk-dentalprofessionals.co.uk.

1. Löe $H$, Schiott $C R$. The effect of mouthrinses and topical application of chlorhexidine on the development of dental plaque and gingivitis in man. J Periodontol Res 1970; 5: 79-83.

2. Löe H, Schiött C R, Karring G, Karring T. Two years use of chlorhexidine in man. J Periodontal Res 1976; 11: 135-144.

3. Van Strydonck DA et al. Effect of chlorhexidine mouthrinse on plaque, gingival inflammation and staining in gingivitis patients: a systematic review. J Clin Periodontol 2012; 39: 1042-1055.

4. Olsen I. Denture Stomatitis. Effects of chlorhexidine and amphotericin $\mathrm{B}$ on the mycotic ora. Acta Odontol Scand 1975; 22: 41-46.

5. GSK Data on File. MMR Research, 2013.

6. Jones C G. Chlorhexidine: is it still the gold standard? Periodontol 2000 1997; 15: 55-62.

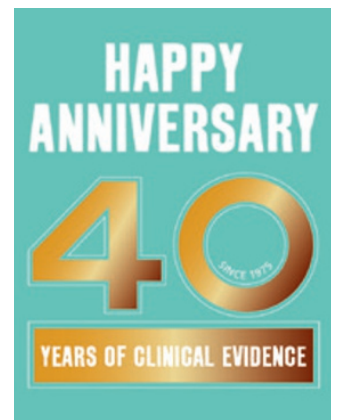

\section{TIPS FROM THE BRIGHTEST IN DENTISTRY}

BDIA Dental Showcase remains the UK's premier dental trade event, but it's also an ideal event to learn new skills and ideas from the dental industry's brightest leaders and recognised experts.

Taking place at the NEC in Birmingham on the 22-24 October, this year's show has a particular focus on the sharing of knowledge. Register for free entry and to see the full lecture programme, go to www.dentalshowcase.com.

Visit the website for full details of exhibitors and visitor information, and you can also download the Showcase app to help you make the most of your visit.

\section{TREATMENT OF THE WORN DENTITION}

Tooth wear is becoming an increasingly common problem in modern day dentistry and there are a large variety of conservative options available for treatment. However, this variety can also lead to confusion and apprehension. Making the right restorative decisions is a key to success.

Mizrahi Dental Teaching is offering a one day comprehensive course presented by Dr Basil Mizrahi that will discuss all aspect of the treatment of various types of tooth wear. It will be clinically oriented and delegates will come away feeling more confident and be able to implement what they have learned into their clinical practice.

Topics covered will include:

- Veneers on worn teeth

- Dahl principle - when and how to use it

- Do you need to treat all the teeth?

- Crowns vs. onlays on posterior teeth

- Increasing the VDO - how to decide when and by how much

- Posterior onlays - preparation design, material choice, how to bond them

- Palatal veneers

- Localised anterior wear $v s$. advanced generalised wear.

The course takes place on 23 tion on this and other upcoming courses contact Mizrahi Dental Teaching by email info@mizrahi-dental-teaching.co.uk or visit www.mizrahi-dental-teaching.co.uk or call 02033942984. October 2015. For more informa-

\section{THE FIRST DIGITALLY PRODUCED ORAL APPLIANCES FOR DEEP, RESTFUL SLEEP}

Many people who still feel tired when they get up in the morning suffer from sleep apnoea. This is caused by a constriction of the airways. With a new piece of software, SICAT Air, dentists can now analyse patients' airways in 3D and plan the appropriate therapy digitally.

There is a new option of digitally imaging the entire process of what is known as obstructive sleep apnoea to producing the appliance. The SICAT Air 3D software makes this possible. With this software, dentist can precisely analyse the patient's airways in an X-ray volume image - and then make an individual treatment plan. This planning also takes the temporomandibular joints and bite movements into consideration so that no stress is exerted there.

The need for solutions such as this is evident from the number of those affected, which is greater than frequently assumed. The HSL sleep laboratory in Heidelberg estimates that two to four percent of adults are affected by this condition. In middle to old age, the frequency is between 15 and 19 percent in men and between 9 and 15 percent in women. Overweight is also a risk factor. The problem is that people who suffer from breathing interruptions at night wake up stressed the next morning. This not only increases the risk of an accident, but also the risk of cardiovascular diseases, diabetes, and many other disorders. The mandibular protrusion appliance can provide considerable relief in many cases.

Working in three dimensional imaging with a selection of products and solutions for dental implantology, functional diagnostics and treatment, as well as oral \& maxillofacial surgery, SICAT focuses on the development of user-friendly and cost-effective software and hardware. For further information call 08450715040 or e-mail info@sironadental.co.uk. 